\title{
Pantoea stewartii subsp. stewartii Produces an Endoglucanase That Is Required for Full Virulence in Sweet Corn
}

\author{
Mojtaba Mohammadi, Lindsey Burbank, and M. Caroline Roper \\ Department of Plant Pathology and Microbiology, 900 University Avenue, University of California, Riverside 92521, U.S.A.
}

Submitted 5 September 2011. Accepted 20 November 2011.

\begin{abstract}
Pantoea stewartii subsp. stewartii, a xylem-dwelling bacterium, is the causal agent of Stewart's wilt and blight of sweet corn. The goal of this study was to characterize the only gene in the $P$. stewartii subsp. stewartii genome predicted to encode an endoglucanase (EGase); this gene was designated engY. Culture supernatants from $P$. stewartii subsp. stewartii and Escherichia coli expressing recombinant EngY protein possessed both EGase and xylanase activities. Deletion of eng $Y$ abolished EGase and xylanase activity, demonstrating that EngY appears to be the major EGase or xylanase produced by $P$. stewartii subsp. stewartii. Most importantly, our results show that EngY contributes to movement in the xylem and disease severity during the wilting phase of Stewart's wilt but is not required for water-soaked lesion formation.
\end{abstract}

Pantoea stewartii subsp. stewartii is a xylem-dwelling bacterium that causes Stewart's wilt, a serious disease of sweet corn (Zea mays). The pathogen is spread by the corn flea beetle (Chaetocnema pulicaria), which transmits the bacteria primarily through scratching wounds created while feeding on the plant (Claflin 2000; Pataky 2004). As P. stewartii subsp. stewartii initially enters the plant, it colonizes the leaf apoplast and causes localized plant cell lysis, producing a characteristic water-soaked lesion. In later infection stages, the pathogen preferentially colonizes the xylem tissue of the plant, where it multiplies to high cell densities and forms exopolysaccharide (EPS)-encased biofilms that block water flow in the xylem, leading to the subsequent wilting and death of the plant (Beck von Bodman and Farrand 1995; Dolph 1988; Leigh and Coplin 1992). Molecular genetic approaches have identified the type III secretion system and stewartan EPS to be important pathogenicity factors for $P$. stewartii subsp. stewartii but, otherwise, the molecular mechanisms that this bacterium utilizes as it infects the sweet corn host are not fully understood (Beck von Bodman and Farrand 1995; Dolph 1988; Leigh and Coplin 1992).

Host cell-wall-degrading enzymes (CWDE) are important virulence factors for many bacterial phytopathogens, including other xylem-dwelling bacteria such as Xylella fastidiosa, Ralstonia solanacearum, and Xanthomonas campestris (Dow et al. 1990, 1998; Gonzalez and Allen 2003; Huang and Allen 1997; Kamoun and Kado 1990; Liu et al. 2004; Ray et al. 2000; Roper et al. 2007). CWDE have specifically been implicated in facilitating systemic movement throughout the xylem tissue (Huang and Allen 2000; Roper et al. 2007). These include

Corresponding author: M. C. Roper; E-mail: mcroper@ucr.edu enzymes that break down the pectic, cellulosic, hemicellulosic, and proteinaceous components of the plant cell wall (Carpita and Gibeaut 1993; Keegstra et al. 1973). In silico analysis of the $P$. stewartii subsp. stewartii genome revealed several open reading frames (ORF) encoding putative host CWDE, including two cellulases, two xylanases, one polygalacturonase, and one endoglucanase (EGase) (ASAP database) (Glasner et al. 2006), indicating that $P$. stewartii subsp. stewartii may be capable of host cell wall degradation.

EGases (EC 3.2.1.4) are hydrolytic enzymes that cleave polymers containing $\beta$-1,4-linked glucose molecules such as those found in cellulose and the cross-linking glycans (hemicellulose), both constituents of the higher plant cell wall (Buchanan et al. 2000). EGases are implicated in virulence and systemic colonization of the xylem in other bacterial phytopathogens, such as $R$. solanacearum and $X$. campestris pv. campestris (Gough et al. 1988; Roberts et al. 1988; Saile et al. 1997). Furthermore, there is also substantial evidence of enzymes classified as EGases, which exhibit xylanase activity in addition to EGase activity (Bauer et al. 1973; Labavitch and Greve 1983).

The most closely related ortholog to the $P$. stewartii subsp. stewartii EngY is the minor EGase Y, called CelY, from $P$. ananatis (99\% coverage, $E=0.0$ ) (De Maayer et al. 2010). CelY has been cloned and characterized from the closely related species Dickeya dadantii and is necessary for full virulence of the pathogen (Boccara et al. 1994; Boyer et al. 1987). Based on the carbohydrate-active enzyme classification, the $P$. stewartii subsp. stewartii EngY belongs to the glycoside hydrolase family 8 , which are O-glycosyl hydrolases that cleave the glycosidic bond between two or more carbohydrates or between a carbohydrate and a noncarbohydrate moiety. This family includes EGases, endo-1,4- $\beta$-xylanase, lichenase, and chitosanase. Enzymes in this family can also hydrolyze $\beta-1,4-$ linkages in $\beta$-D-glucans containing $\beta$-1,3 linkages (i.e., the socalled mixed-linkage $\beta$-glucans found in cereal plant cell walls) and xylan (Labavitch and Greve 1983). Carboxy methyl cellulose (CMC) is a soluble form of cellulosic glucan composed of $\beta-1,4$ carboxymethyl group-substituted glucosyl residues. The mixed-linkage $\beta$-D-glucan is a polymer primarily composed of $\beta$-1,4-linked glucosyl residues interspersed with $\beta-1,3$-linked glucosyl residues. Xylans are polymers of $\beta-1,4-$ linked xylosyl residues with varying degrees of substitution by arabinosyl or glucusonosyl residues. All represent structural carbohydrates that are found in sweet corn cell walls (Buchanan et al. 2000).

Because of the presence of putative CWDE genes in the genome of $P$. stewartii subsp. stewartii and its lifestyle as a xylemdwelling bacterium, we hypothesized that CWDE allow P. stew- 
artii subsp. stewartii to colonize the xylem by digesting xylem pit membranes that separate xylem vessels. This would, presumably, facilitate movement within the xylem and potentially enable the bacteria to utilize the cell wall structural carbon-rich nutrients released by this enzymatic activity. In this study, we confirmed that the eng $Y$ ORF encodes a functional EGase that is capable of degrading substrates containing $\beta$-1,4-linked glucosyl and xylosyl residues similar to those that $P$. stewartii subsp. stewartii would encounter in sweet corn cell walls, and that a deletion in the eng $Y$ gene abolishes this enzymatic activity. We also demonstrate that EngY is an important virulence factor that contributes to the systemic infection of sweet corn.

\section{RESULTS}

\section{Culture supernatants of $P$. stewartii subsp. stewartii} possess EGase and xylanase activity.

We tested precipitated proteins from $P$. stewartii subsp. stewartii DC283 culture supernatants for the ability to degrade three polysaccharide substrates: CMC, a mixed-linkage $\beta$-D-glucan, and xylan. EGase and xylanase activities were confirmed by the production of reducing-end groups (micrograms of glucose released per milligram of protein) when assayed in the presence of $\mathrm{CMC}$, mixed-linkage $\beta$-D-glucan, and xylan (Fig. 1A to $\mathrm{C}$ ). The results represent the means of enzyme activities expressed as micrograms of glucose equivalent released per milligram of protein. We also tested enzymatic activity associated with the cell pellet (data not shown) but found that the majority of the EGase and xylanase activity was found in the culture supernatant, indicating that the enzyme capable of degrading these three substrates is primarily secreted from the cell.

\section{Enzymatic activity}

of the EngY protein expressed in Escherichia coli.

The precipitated culture supernatants from Escherichia coli BL21 (pEXP2::engY) expressing the P. stewartii subsp. stewartii EngY protein were capable of degrading CMC, mixed-linkage $\beta$-D-glucan, and xylan, as indicated by the production of reducing ends when incubated with these substrates (Fig. 2A to C). The $\beta$-1,4-linked glucan and xylan backbones look alike in terms of sugar ring size (both have six-membered rings) and the hydroxyl group orientations of the glucose and xylose residues in the polymer backbone are the same. Accordingly, it is not uncommon that EGases also possess xylanase activity (Bauer et al. 1973; Labavitch and Greve 1983). The pEXP2-GW/lacZ vector supplied with the pDEST expression kit (Invitrogen, Grand Island, NY, U.S.A. ) served as the negative control in these experiments, and precipitated proteins from E. coli harboring
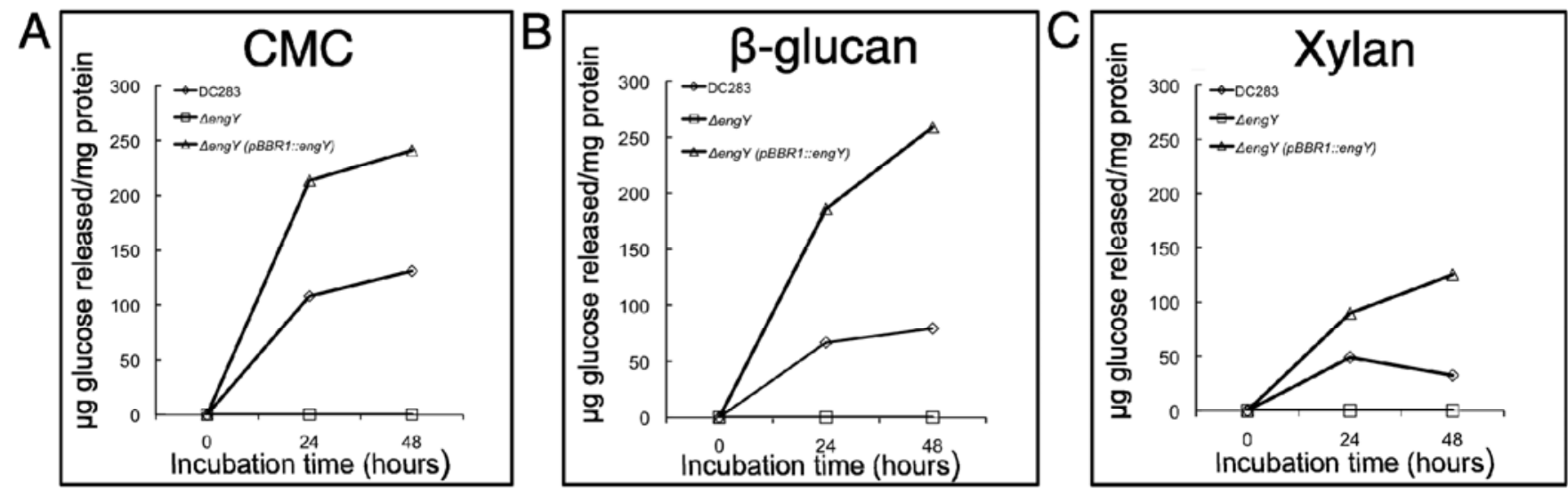

Fig. 1. Enzymatic activity of proteins precipitated from Pantoea stewartii subsp. stewartii culture supernants. Degradation of either A, carboxymethyl cellulose sodium salt (CMC); $\mathbf{B}$, mixed-linkage $\beta$-D-glucan ( $\beta$-glucan) from barley bran; or $\mathbf{C}$, beech wood xylan as indicated by the production of reducing ends in reaction mixtures of proteins precipitated from the culture supernatants of either $P$. stewartii subsp. stewartii DC283, $\Delta e n g Y$, or the complemented strain, $\Delta$ eng $Y$ (pBBR1::eng $Y$ ) as a function of time. Reaction mixtures were incubated at $37^{\circ} \mathrm{C}$ overnight. Similar results were obtained from at least three independent experiments and the results represent the mean of three replicates from one representative experiment.
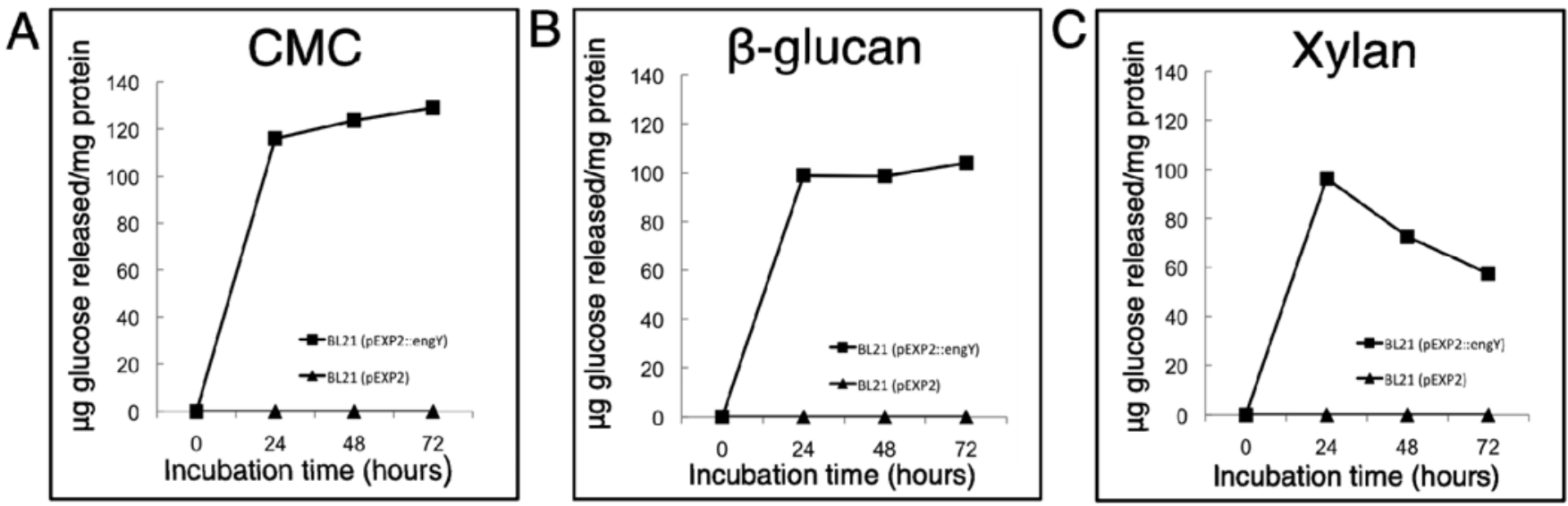

Fig. 2. Enzymatic activity of the EngY protein expressed in Escherichia coli. Degradation of either A, carboxymethyl cellulose sodium salt (CMC); B, mixed-linkage $\beta$-D-glucan ( $\beta$-glucan) from barley bran; or $\mathbf{C}$, beech wood xylan as indicated by the production of reducing ends in reaction mixtures of proteins precipitated from the culture supernatants of either E. coli BL21(DE3) pLysS carrying pEXP2::engY, or BL21(DE3) pLysS carrying the negative control vector pEXP2-DEST::lacZ as a function of time. Reactions mixtures were incubated at $37^{\circ} \mathrm{C}$ overnight. Similar results were obtained from at least three independent experiments and the results represent the mean of three replicates from one representative experiment. 
this plasmid did not break down the substrates tested in the reducing sugar assay. These results confirm that the engY ORF encodes an enzyme that is capable of degrading polymers contain $\beta$-1,4-linked glucosyl and xylosyl residues molecules.

\section{A deletion mutation in $P$. stewartii subsp. stewartii eng $Y$ abolishes EGase and xylanase activity.}

We constructed a targeted deletion in the P. stewartii subsp. stewartii eng $Y$ gene. To determine whether EngY was solely or partially responsible for the EGase or xylanase activity measured in $P$. stewartii subsp. stewartii DC283 supernatants, we determined the ability of the $\Delta e n g Y$ mutant to degrade CMC, a mixed-linkage $\beta$-D-glucan, and xylan using a reducing sugar assay. Proteins precipitated from the culture supernatants of strain $\Delta e n g Y$ lacked the ability to degrade all three substrates (Fig. 1A to C). Furthermore, complementation with a wildtype (WT) copy of eng $Y$ in strain $\Delta e n g Y$ (pBBR1::eng $Y$ ) restored CMCase, xylanase, and mixed-linkage $\beta$-glucanase activities to levels that exceeded that of the WT. This is likely due to the fact that the eng $Y$ gene was cloned into the multicopy pBBR1-MCS4 complementation vector and expression was driven off of the strong lacZ promoter in addition to the native promoter. These results indicate that the enzyme encoded by the eng $Y$ gene is the primary EGase or xylanase produced by $P$. stewartii subsp. stewartii in vitro.

\section{EngY is required}

\section{for full virulence and movement in planta.}

There are two phases of Stewart's wilt: leaf blight and wilt. In the leaf blight phase, the bacteria primarily colonize the leaf

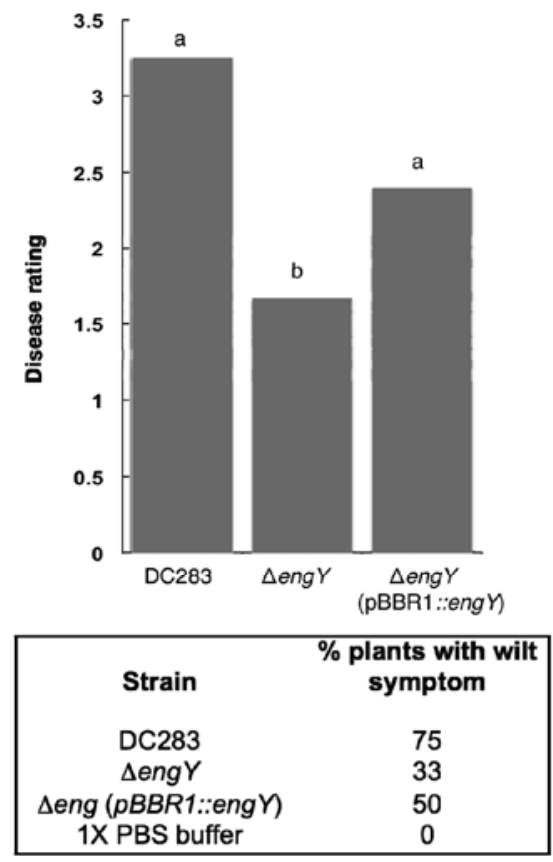

Fig. 3. Contribution of EngY to virulence. Fourteen-day-old sweet corn seedlings ('Jubilee') were inoculated with $5 \mu \mathrm{l}$ of either Pantoea stewartii subsp. stewartii DC283; $\Delta e n g Y$; the complemented strain, $\Delta e n g Y$ (pBBR1::engY); or $1 \times$ phosphate-buffered saline (PBS) Tween 20 buffer using the scratch-inoculation technique. Virulence was assessed 8 days post inoculation on a 0-to-5 rating scale. Data represent the mean of at least 12 replicates. Similar results were obtained from at least three independent experiments. Disease severity data was analyzed using a six-bytwo $\chi^{2}$ contingency table analysis and letters indicate treatments that are significantly different from one another at $P \leq 0.05$. Plants inoculated with $1 \times$ PBS Tween 20 buffer did not develop any Stewart's wilt symptoms. The table summarizes the percentage of plants displaying wilt symptoms (rating 3 or more on the disease index scale). apoplast, causing the formation of water-soaked lesions to appear on the leaves. In the wilting phase, the bacteria systemically colonize the xylem, where they reach high population numbers leading to the blockage of water flow in the xylem tissue. When $P$. stewartii subsp. stewartii is inoculated into the whorl of a sweet corn seedling, the bacteria only colonize the leaf apoplast and do not enter the xylem. Therefore, this method specifically tests the ability to form water-soaked lesions (Coplin et al. 1986). We saw no difference in virulence on sweet corn seedlings when the $\Delta e n g Y$ and $P$. stewartii subsp. stewartii DC283 strains were individually whorl inoculated (data not shown), indicating that EngY has no obvious role in water-soaked lesion formation.

In contrast, when the bacteria were inoculated using the stem-scratch technique, we saw a decrease in the ability of the $\Delta e n g Y$ strain to cause wilting. The stem inoculation technique mimics wounding created by the corn flea beetle vector during feeding, deposits the bacteria into the apoplast and the xylem, and tests the ability to incite both leaf blight and wilt symptoms. Scratch-inoculated plants challenged with $P$. stewartii subsp. stewartii DC283 exhibited the typical water-soaked lesions, ooze, and wilt symptoms associated with Stewart's wilt. These inoculated plants averaged 3.25 on the disease index scale and $75 \%$ were wilted (Fig. 3). However, the plants inoculated with the $\Delta e n g Y$ strain developed fewer wilt symptoms than those inoculated with $P$. stewartii subsp. stewartii DC283, rated an average of 1.67 on the disease index scale, and only $33 \%$ developed wilting symptoms (Fig. 3). The reduced wilting phenotype for the $\Delta e n g Y$ strain was partially complemented with a WT copy of eng $Y$ supplied on plasmid pBBR1::eng $Y$ (Fig. 3). Contingency table analysis showed that the disease ratings for plants inoculated with $\Delta e n g Y$ were statistically different from those of the plants inoculated with WT P. stewartii

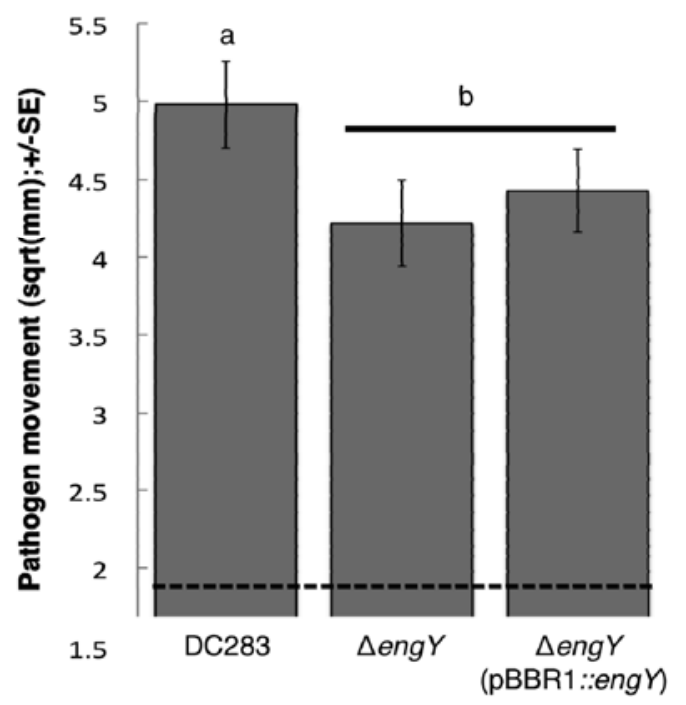

Fig. 4. EngY plays a role in acropetal dissemination within the xylem. Dissemination was measured by inoculating approximately $10^{7}$ green fluorescent protein (GFP)-tagged bacteria into the midrib of 14-day-old sweet corn ('Jubilee') seedling leaves and evaluated after $72 \mathrm{~h}$ of incubation. Active bacterial dissemination within the xylem of sweet corn (Jubilee) seedlings was assessed by epifluorescence microscopy measured against the passive infiltration of fluorescent microspheres. The dashed line indicates the distance the fluospheres traveled. The GFP-labeled wild-type strain DC283 showed significant dissemination in the acropetal direction (toward base of the leaves) direction, whereas the GFP-labeled $\Delta e n g Y$ mutant strain did not move significantly beyond the passive infiltration distance of the fluorescent microspheres. Data were analyzed using a one-way analysis of variance test and each statistical mean was square-root transformed to meet test assumptions. The graph represents the means from at least three biological replicates each with at least 10 technical replicates. 
subsp. stewartii DC283 or the complemented strain, $\Delta e n g Y$ carrying pBBR1::eng $Y(P=0.001)$. The $\Delta e n g Y$ scratch-inoculated plants developed a similar level of leaf blight symptoms (water-soaking) when compared with $P$. stewartii subsp. stewartii DC283 inoculated plants (data not shown). These results demonstrate that EngY is required for wilting but not watersoaked lesion formation.

The pores in the pit membranes that separate one xylem vessel from another in corn plants are too small to allow passage of bacteria (Shane et al. 2000). In order to breach the pit membrane barrier, $P$. stewartii subsp. stewartii must actively digest them, likely through the action of glycosyl hydrolases, such as EngY, that are capable of degrading the polysaccharide constituents of that compose the xylem pit membranes. We tracked the movement of a green fluorescent protein (GFP)-labeled $\Delta e n g Y$ mutant in the xylem of sweet corn by placing the inoculum in a leaf wound and compared it with the movement of GFP-labeled WT P. stewartii subsp. stewartii DC283. Movement was assessed $72 \mathrm{~h}$ later by fluorescence microscopy. We compared acropetal and basipetal movement of the pathogen away from the point of inoculation using a one-way analysis of variance to test differences among means, and the movement values were square-root transformed to meet test assumptions. Statistical significance was tested at the 5\% confidence level. Our results show that $\Delta e n g Y$ (pHC60::gfp) was compromised in acropetal (Fig. 4) but not basipetal (data not shown) movement within the xylem. Acropetal movement was partially restored in strain $\Delta e n g Y$ (pBBR1::engY) (pHC60:gfp) that carries a WT copy of engY.

\section{DISCUSSION}

In this study, we identified and characterized an EGase or xylanase for the phytopathogen $P$. stewartii subsp. stewartii and demonstrated that this EGase can degrade complex polysaccharide substrates containing $\beta$-1,4-linked glucosyl or $\beta-1,4-$ linked xylosyl backbones similar to those found in corn plant cell walls. Most importantly, our data demonstrate that this enzyme contributes to virulence and dissemination within the xylem.

P. stewartii subsp. stewartii systemically colonizes the xylem, which results in the wilting of young seedlings. Xylem vessels are separated by diaphragm-like structures that function as filters that block the passage of particulates, microbes, and air embolisms from one xylem vessel to another. These filters, while typically referred to as pit membranes, are actually made of primary plant cell wall tissue (Esau 1965). Primary plant cell walls are composed of cellulose microfibrils embedded in a polysaccharide matrix of pectin and cross-linking glycans (hemicellulose) (Buchanan et al. 2000; Gibeaut and Carpita 1994). Sweet corn is a commelinoid monocot and the major cross-linking glycan in this group of plants is glucuronoarabinoxylan (GAX). GAX consists of a backbone of $\beta$-1,4-linked xylosyl residues with side chains of glucuronic acid and arabinose (Buchanan et al. 2000; Gibeaut and Carpita 1994). In addition, members of the plant order Poales, which includes sweet corn, contain a unique mixed-linkage $\beta$-glucan. This polymer is primarily composed of cellotriose and cellotetraose (three and four $\beta$-1,4-linked glucosyl residues, respectively) connected by $\beta-1,3$ linkages (Buchanan et al. 2000; Carpita 1996).

The small pores in the pit membrane have been estimated to be between 5 and $20 \mathrm{~nm}$ in other plant species (Choat et al. 2003; Perez-Donoso et al. 2010; Zimmerman 1983) and the pores in the Z. mays pit membranes are estimated to be $4.9 \pm$ $0.7 \mathrm{~nm}$ in size (Shane et al. 2000), which is much too small to allow passive passage of a $P$. stewartii subsp. stewartii cell, which is 400 to 700 by 900 to 2,000 $\mathrm{nm}$ in size (Bradbury 1967). How P. stewartii subsp. stewartii breaches this barrier is poorly understood. We speculated that the bacterium utilizes plant CWDE to digest xylem pit membranes because it is a strategy used by other xylem-inhabiting phytopathogenic bacteria to facilitate movement through the xylem tissue (Huang and Allen 2000; Roper et al. 2007). P. stewartii subsp. stewartii may also potentially metabolize the cell wall structural carbon-rich nutrients released by this enzymatic activity. We chose the commercially available model substrates CMC, mixed-linkage $\beta$-glucan, and xylan because they most closely represent the structures of cellulosic glucans and hemicellulosic glycans (GAX), and hemicellulosic glucans (mixed-linkage $\beta$-D-glucan) that $P$. stewartii subsp. stewartii would presumably encounter in the pit membranes found in sweet corn xylem conduits, and demonstrated that the P. stewartii subsp. stewartii EngY degraded all three of these substrates. The enzymatic action of EngY may aid in passage through xylem pit membranes or contribute to release of nutrients from the host cell wall by digesting the cross-linking glycans and, possibly, cellulose found in the primary walls of sweet corn.

When tested in planta, we confirmed that the $\Delta e n g Y$ mutant was significantly compromised in the ability to move acropetally within the xylem, indicating that loss of the ability to degrade $\beta$-1,4-linked glucans or xylans results in decreased movement in the xylem. We also found that EngY contributes to disease severity during the wilting phase of Stewart's wilt but not during the water-soaking (leaf blight) phase. This suggests that the impairment in dissemination throughout the xylem leads to a reduction in wilt disease development in sweet corn. This was similarly demonstrated in $R$. solanacearum, where inactivation of a single EGase caused a partial reduction of wilting in tomato when wound inoculated into tomato stems and also hindered systemic colonization of the xylem (Roberts et al. 1988; Saile et al. 1997).

Because of the variety of other polysaccharide types expected to be present in sweet corn cell walls, it is likely that $P$. stewartii subsp. stewartii also utilizes other CWDE to facilitate its growth in the apoplast and xylem vessels. Several ORF encoding putative $\beta-1,4$ cellulases and xylanases and one polygalacturonase $(\mathrm{PG})$ have been identified in the $P$. stewartii subsp. stewartii genome and these may also be involved in degradation of the hemicellulosic and pectic portions of the plant cell wall. However, these are apparently not required for degradation of $\mathrm{CMC}$, mixed-linkage $\beta$-D-glucan, or xylan because a mutation in eng $Y$ completely abolished enzymatic activity against all three of these substrates. This does not completely rule out the role of the other putative cellulases or xylanases that may be contributing to hemicellulose degradation in planta because the enzymatic assays conducted in this study were performed with $P$. stewartii subsp. stewartii cells grown in rich culture medium. These enzymes could be expressed during the infection process while remaining undetectable in culture supernatants. Degradation of crystalline cellulose is a complex process and usually involves the coordinated activities of multiple enzymes, such as EGases and cellobiohydrolases, which often exist in complexes called cellulosomes (Bayer et al. 2004). P. stewartii subsp. stewartii cannot be considered truly cellulolytic because it does not appear to possess the full suite of enzymes necessary for complete hydrolysis of crystalline cellulose and likely cannot completely digest the cellulose that is found in the microfibrils of the cell wall. Thus, we speculate that EngY is primarily involved in breaking down the cross-linking glycans rather than cellulose microfibrils.

In other systems, the pectic matrix plays a critical role establishing the pore size of the pit membranes (Baron-Epel 1988; Buchanan et al. 2000; Perez-Donoso et al. 2010; Zwieniecki et 
al. 2001). PG hydrolyze pectin polymers and are involved in the systemic colonization of the xylem for some xylem-dwelling bacterial pathogens (Huang and Allen 2000; Perez-Donoso et al. 2010; Roper et al. 2007). One ortholog to a PG was identified in the $P$. stewartii subsp. stewartii genome. Although pectinase (PG or pectate lysase) activity was not detected in $P$. stewartii subsp. stewartii culture supernatants or cell pellets (M. C. Roper, unpublished data), this does not preclude the possibility of pectinase production in planta. Pectins are in relatively low amounts in cereal cell walls but their abundance in pit membranes is unknown and they could play a key role in dictating pit membrane porosity as in other plant systems. Until immunohistochemical assays as performed with grapevine pit membranes (Sun et al. 2011) are executed in sweet corn, this question will remain unanswered.

The xylem sap is considered to have a dilute nutrient composition with a relatively limited availability of a carbon source. Despite this assumption, P. stewartii subsp. stewartii can reach high cell densities in the xylem (approximately $10^{10}$ $\mathrm{CFU} / \mathrm{g}$ of plant tissue) and, while doing so, produces copious amounts of a carbohydrate-rich stewartan EPS (Nimtz et al. 1996), which suggests that the bacteria must have access to an ample carbon source in the xylem. As plant cell walls are being synthesized, the cell wall polymers remain soluble until they are cross-linked at the cell's exterior surface. It is reasonable to speculate that $P$. stewartii subsp. stewartii takes advantage of the transient availability of these soluble cell wall precursors as they are being synthesized and deposited in the cell wall in developing xylem tissue (Buchanan et al. 2000). Mixedlinkage $\beta$-D-glucans are one of the few known developmentalstage-related polysaccharides in plants, and they accumulate to approximately $30 \%$ of the noncellulosic corn coleoptile cell wall polysaccharide material during cell elongation and enlargement (Hoson et al. 1992; Inouhe and Nevins 1991a,b). Synthesis and hydrolysis of these $\beta$-D-glucans occurs simultaneously during growth and they are presumably relatively abundant in young, rapidly growing sweet corn seedlings.
Young sweet corn seedlings are highly susceptible to Stewart's wilt compared with mature corn plants and it is perhaps the metabolism of the mixed-linkage $\beta$-D-glucan that $P$. stewartii subsp. stewartii exploits as it colonizes rapidly growing seedlings.

A possible role for the EGase in virulence is implied by its potential to degrade plant cell wall components (i.e., glucans or xylans). EngY plays a small role in dissemination of the pathogen throughout the xylem tissue and may facilitate degradation of cell wall material by other enzymes (i.e., pectinase and protease). Furthermore, EngY could possibly participate in the release of carbohydrates found in the plant cell wall that could be utilized as nutrients. This study is the first account of host CWDE being produced by $P$. stewartii subsp. stewartii and offers insight into the mechanisms of virulence this pathogen uses as it invades and colonizes sweet corn plants.

\section{MATERIALS AND METHODS}

\section{Strains and growth conditions.}

P. stewartii subsp. stewartii (DC283) and E. coli strains were cultured and maintained on nutrient agar and Luria-Bertani (LB) agar (Becton Dickinson, Franklin Lakes, NJ, U.S.A.). For enzyme, protein, and nucleic acid extractions, bacterial strains were grown in LB liquid medium. Nalidixic acid $(30 \mu \mathrm{g} / \mathrm{ml})$, kanamycin (Kan) $(25 \mu \mathrm{g} / \mathrm{ml})$, streptomycin $(100 \mu \mathrm{g} / \mathrm{ml})$, spectinomycin $(100 \mu \mathrm{g} / \mathrm{ml})$, ampicillin $(100 \mu \mathrm{g} / \mathrm{ml})$, and tetracycline $(10 \mu \mathrm{g} / \mathrm{ml})$ were added to the medium when appropriate. Bacterial strains and plasmids are presented in Table 1.

\section{Construction of the $P$. stewartii subsp. stewartii $\Delta e n g Y$ mutant.}

The $\Delta e n g Y$ mutant was constructed based on a previously described method (Choi and Schweizer 2005) that utilizes Gateway cloning technology (Invitrogen). The flanking regions of the eng $Y$ gene (500 bp upstream of the start codon and $500 \mathrm{bp}$ downstream of the stop codon) were amplified separately from

Table 1. Bacterial strains and plasmids used in this study

\begin{tabular}{|c|c|c|}
\hline Strain or plasmid & Relevant genotypes $^{\mathrm{a}}$ & Reference or source \\
\hline \multicolumn{3}{|c|}{ Strains } \\
\hline \multicolumn{3}{|c|}{ Pantoea stewartii subsp. stewartii } \\
\hline DC283 & SS104 WT, Nal ${ }^{r}$ & Coplin et al. 1986 \\
\hline$\Delta e n g Y$ & Deletion of eng $Y, \mathrm{Nal}^{\mathrm{r}}$ & This study \\
\hline \multicolumn{3}{|l|}{ Escherichia coli } \\
\hline BL21 & 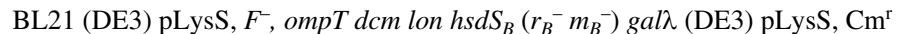 & Promega Corp. \\
\hline DH10 & $F^{-}$endA1 recA1 galE15 galK16 nupG rpsL $\triangle$ lacX74 Ф80lac Z $1 M 15$ araD139 & \\
\hline & $\Delta($ ara,leu $) 7697 \mathrm{mcrA} \Delta(\mathrm{mrr}-\mathrm{hs} d R \mathrm{MS}-\mathrm{mcrBC}) \lambda^{-}$ & Invitrogen \\
\hline EC100pir ${ }^{+}$ & $\begin{array}{l}\text { F mcrA (mrr-hsdRMS-mcrBC) 80dlacZ M15 } \triangle \text { lacX74 recA1 endAlaraD139 } \\
\text { (ara, leu)7697galU galK } \lambda^{-} \text {rpsL nupG pir+(DHFR) }\end{array}$ & Epicentre \\
\hline 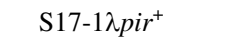 & $\mathrm{RP} 4, \mathrm{Mob}+, \mathrm{Sm}^{\mathrm{r}}$ & Simon et al. 1982 \\
\hline \multicolumn{3}{|l|}{ Plasmids } \\
\hline pKD4 & Kanamycin cassette, $\mathrm{Ap}^{\mathrm{r}}, \mathrm{Km}^{\mathrm{r}}$ & Datsenko and Wanner 2000 \\
\hline pDONR-Zeo & Cloning vector, $\mathrm{Zeo}^{\mathrm{r}}$ & Invitrogen \\
\hline pAUC40 & Suicide vector, Gateway attR-Cmr cassette cloned in pKNG101 $\mathrm{Sm}^{\mathrm{r}}, \mathrm{Cm}^{\mathrm{r}}$ & Carlier et al. 2009 \\
\hline pBBR1MCS-4GW & pBBR1MCS-4 modified as a Gateway destination vector & $\begin{array}{l}\text { Carlier et al. 2009; } \\
\text { Kovach et al. } 1995\end{array}$ \\
\hline pKNG101 & Suicide vector, $\mathrm{Sm}^{\mathrm{r}}$ & Kaniga et al. 1991 \\
\hline pFLP2 & $s a c B^{+}$, source of FLP recombinase, $\mathrm{Ap}^{\mathrm{r}}$ & Hoang et al. 1998 \\
\hline pHC60::gfp & Broad host range vector carrying $g f p, \mathrm{Tc}^{\mathrm{r}}$ & Cheng and Walker 1998 \\
\hline pMOJ1 & eng $Y:: k a n$ cloned into pDONR-Zeo, $\mathrm{Km}^{\mathrm{r}}$ & This study \\
\hline pMOJ3 & eng $Y:$ :kan cloned into $\mathrm{pKNG} 101, \mathrm{Km}^{\mathrm{r}}, \mathrm{Sm}^{\mathrm{r}}$ & This study \\
\hline pBBR1::eng $Y$ & eng $Y$ cloned into pBBR1MCS-4GW, Ap ${ }^{\mathrm{r}}$ & This study \\
\hline pMOJ9 & pCR8/GW/TOPO::engY ORF, $\mathrm{Sp}^{\mathrm{r}}$ & This study \\
\hline pEXP2 & Gateway compatible expression vector pEXP2-DEST::lacZ & Invitrogen \\
\hline pEXP2::eng $Y$ & eng $Y$ cloned into $\mathrm{pEXP} 2, \mathrm{Ap}^{\mathrm{r}}$ & This study \\
\hline pEXP2-GW/lacZ & pEXP2-DEST control plasmid, $\mathrm{Ap}^{\mathrm{r}} \mathrm{Zeo}^{\mathrm{r}}$ & Invitrogen \\
\hline
\end{tabular}

${ }^{a} \mathrm{Nal}^{\mathrm{r}}, \mathrm{Cm}^{\mathrm{r}}, \mathrm{Sm}^{\mathrm{r}}, \mathrm{Ap}^{\mathrm{r}}, \mathrm{Km}^{\mathrm{r}}, \mathrm{Zeo}^{\mathrm{r}}, \mathrm{Tc}^{\mathrm{r}}$, and $\mathrm{Sp}^{\mathrm{r}}$ indicate resistance to nalidixic acid, chloramphenicol, streptomycin, ampicillin, kanamycin, zeocin, tetracycline, and spectinomycin, respectively; $g f p=$ green fluorescent protein gene. 
P. stewartii subsp. stewartii DC283 genomic DNA using primer pairs GW-engF/engR-Kan for the upstream flanking region and engF-Kan/engR for the downstream flanking region (Table 2) using optimized polymerase chain reaction (PCR) conditions. The Kan resistance marker $(1.4 \mathrm{~kb})$ was amplified from the pKD4 plasmid (Datsenko and Wanner 2000) using pKD4fwd and pKD4rev primers designed to overlap the $5^{\prime}$ and $3^{\prime}$ flanking regions of the eng $Y$ amplicons and Kan cassette, respectively. In a second round of PCR, the three purified DNA fragments generated from the first round were combined into one tube (without primers) and assembled by PCR overlap extension: primer pair GWattB1/GWattB2 was added after 10 rounds of PCR and then the rest of the PCR reaction was carried out. The assembled PCR product containing attP recombination sites was then recombined into the pDONR/Zeo vector (Invitrogen) using the Gateway BP clonase II mix (Invitrogen) following the manufacturer's instruction to create pMOJ1. pMOJ1 was recombined into pKNG101-attR using the LR clonase II kit according to manufacturer's instruction (Invitrogen) to create pMOJ3. pMOJ3 was introduced into $E$. coli $\mathrm{S} 17-1 \lambda$ by electroporation and was then conjugally transferred into P. stewartii subsp. stewartii DC283. The merodiploid state was resolved by sucrose counter-selection. Sucrose-resistant colonies were selected for Kan resistance and streptomycin susceptibility and doublecrossover events were confirmed by PCR using primers endoglucchkfwd/endoglucchkrev. Following marker-exchange mutagenesis, the Kan cassette used for selection was excised by Flp recombinase carried on pFLP2 (Hoang et al. 1998), leaving an 85-bp frt scar to create the unmarked strain $\Delta e n g Y$.

For complementation analysis, the entire coding region of eng $Y$, including the native promoter and ribosomal binding site, was amplified by PCR using primers endoglucfwd/ endoglucrev. The resulting PCR products were cloned into pCR8/GW/TOPO (Invitrogen) to create pMOJ9. The engY ORF in pMOJ9 was recombined into the Gateway compatible pBBR1MCS4-GW vector (Carlier et al. 2009; Kovach et al. 1995), which contains attR sites, using the Gateway LR clonase II reaction mix (Invitrogen) to create pBBR1::engY. The pBBR1::eng $Y$ construct was checked by sequencing to ensure that there were no introduced mutations and then electroporated into $\Delta e n g Y$ to create strain $\Delta e n g Y$ (pBBR1::engY).

\section{Extraction and precipitation of proteins from culture supernatants.}

Single colonies of $P$. stewartii subsp. stewartii DC283, $\Delta e n g Y$, and $\Delta e n g Y(\mathrm{pBBR} 1:: e n g Y)$ were grown overnight in 2 $\mathrm{ml}$ of LB broth. A 125-ml Bellco flask containing $25 \mathrm{ml}$ of LB broth was inoculated with $250 \mu \mathrm{l}$ of the overnight culture and grown at $28^{\circ} \mathrm{C}, 200 \mathrm{rpm}$. Cells were grown to an optical density at $600 \mathrm{~nm}\left(\mathrm{OD}_{600}\right)$ of 1.0 and collected by centrifugation. Total proteins in the culture supernatant were precipitated by slowly adding ammonium sulfate to $85 \%$ saturation on ice. The precipitated proteins were centrifuged and resuspended in $2 \mathrm{ml}$ of $100 \mathrm{mM}$ sodium acetate buffer ( $\mathrm{pH} \mathrm{6.0)}$ and dialyzed overnight against 3 liters of the same buffer at $4^{\circ} \mathrm{C}$ with stirring in regenerated cellulose dialysis tubing $(\mathrm{MWCO}=12,000$ to 14,000) (Fisherbrand, Fisher Scientific, Pittsburgh). The dialysate was used for downstream enzymatic assays.

\section{Enzymatic activity assays.}

The ability of the P. stewartii subsp. stewartii strains to digest three different substrates-CMC sodium salt (Fisher Scientific), mixed-linkage $\beta$-D-glucan from barley bran (Sigma-Aldrich, St. Louis), and xylan from beech wood (Sigma-Aldrich)—was tested. These substrates were chosen because of their structural similarities to carbohydrate polymers typically found in sweet corn cell walls. A reducing sugar assay was used to demonstrate enzymatic activity based on a protocol described by Dygert and associates (1965). Substrates were dissolved in 100 $\mathrm{mM}$ sodium acetate buffer ( $\mathrm{pH}$ 6.0) to a final concentration of $1.0 \mathrm{mg} / \mathrm{ml}$ by heating briefly and vortexing. A $0.5-\mathrm{ml}$ sample of the dialysate from the ammonium-sulfate-precipitated culture supernatants was incubated with $0.5 \mathrm{ml}$ of each substrate individually. Protein extract incubated without substrate and substrate incubated without protein extract served as enzyme and substrate blanks, respectively. The reaction mixtures and controls were incubated in a $37^{\circ} \mathrm{C}$ water bath for $48 \mathrm{~h}$. Reaction mixture $(50 \mu \mathrm{l})$ was transferred into a screw-cap tube and mixed with $1 \mathrm{ml}$ of reagent $\mathrm{A}$ ( $40 \mathrm{~g}$ of $\mathrm{Na}_{2} \mathrm{CO}_{3}, 16 \mathrm{~g}$ of glycine, and $450 \mathrm{mg}$ of $\mathrm{CuSO}_{4} \cdot 5 \mathrm{H}_{2} \mathrm{O}$ per liter in $\mathrm{diH}_{2} \mathrm{O}$ ) and $1 \mathrm{ml}$ of reagent $\mathrm{B}$ (neocuproine- $\mathrm{HCl}$ at $1.2 \mathrm{~g} / \mathrm{liter}$ in $\mathrm{diH}_{2} \mathrm{O}$ ). Each sample was vortexed and boiled for $12 \mathrm{~min}$ and cooled down to room temperature. The OD was read at $454 \mathrm{~nm}$ using a Biomate $3 \mathrm{UV} /$ visible spectrophotometer (Thermo Scientific, Waltham, MA, U.S.A.). D-glucose at final concentrations of 5, 10,15 , and $20 \mu \mathrm{g}$ was used to obtain a calibration curve. Absorbance values for buffer blank, substrate blank, and enzyme blank were subtracted from the corresponding enzyme or substrate reaction samples and then converted to nanograms of reducing sugar. Total soluble protein concentration in culture supernatant was measured following the Bradford method using the Quick Start Bradford dye Reagent 1× (Bio-Rad Laboratories, Hercules, CA, U.S.A.) (Bradford 1976). Bovine serum albumin fraction IV at 5, 10, 25, 50, and $100 \mu \mathrm{g}$ in $2 \mathrm{ml}$ of

Table 2. List of primer sequences used in this study

\begin{tabular}{|c|c|c|}
\hline Primer & Primer sequence $^{a}$ & Source \\
\hline pKD4fwd & GAGAATAGGAACTTCGGAATAGGAACTTCAA & This study \\
\hline pKD4rev & СTATTCTCTAGAAAGTATAGGAACTTCAGAGCG & This study \\
\hline $\mathrm{GW}$-attB1 ${ }^{\mathrm{b}}$ & GGGGACAAGTTTGTACAAAAAAGCAGGCT & Choi and Schweizer 2005 \\
\hline GW-attB2 ${ }^{b}$ & GGGGACCACTTTGTACAAGAAAGCTGGGT & Choi and Schweizer 2005 \\
\hline GW-endogluc upstream flank fwd ${ }^{c}$ & TACAAAAAAGCAGGCTCAGCTCTATTTCCGCTACCTGTTC & This study \\
\hline Endogluc upstream flank rev-Kan ${ }^{\mathrm{d}}$ & gaacttcgaagcagetccagcetaCAGAGCACCTTATTGATATCGGAAATGC & This study \\
\hline Endogluc downstream flank fwd-Kan ${ }^{\mathrm{d}}$ & cggaataggaactaaggaggatattcatatgTGATGCCCGCTCTGCGGCATGCTGTT & This study \\
\hline GW-endogluc downstream flank rev ${ }^{c}$ & TACAAGAAAGCTGGGTTTTCGAAGTTCGCATGCAGCGCCTGG & This study \\
\hline Endoglucchkfwd & ATAAAGATGTCACGATTGGCGGGC & This study \\
\hline Endoglucchkrev & AAAGCGGTAAGGTGATTTGCACCG & This study \\
\hline Endoglucfwd $\left(-150\right.$ upstream ORF) ${ }^{\mathrm{e}}$ & AGACGGCATTTGCTGCCATTCT & This study \\
\hline Endoglucrev & ATCAGGCGCGTGCTTCTCCT & This study \\
\hline
\end{tabular}

\footnotetext{
${ }^{a}$ Primer sequences are oriented from $5^{\prime}$ to $3^{\prime}$.

${ }^{\mathrm{b}}$ Gateway sequences are in bold

${ }^{\mathrm{c}}$ Gateway overlapping sequences in target gene are shown in bold.

${ }^{\mathrm{d}}$ Kanamycin (Kan) overlapping sequences in target genes are presented in lowercase bold.

${ }^{\mathrm{e}} \mathrm{ORF}=$ open reading frame.
} 
reagent was used as a standard. After 20 min of incubation, absorbance was read at $595 \mathrm{~nm}$. Enzyme activities were reported as nanograms of glucose equivalent released per milligram of protein.

\section{Cloning and expression}

of $P$. stewartii subsp. stewartii EngY in E. coli.

The engY ORF was subcloned from pMOJ9 into the expression vector $\mathrm{pEXP} 2$-DEST (Invitrogen) using the Gateway LR clonase II reaction mix (Invitrogen) to create $\mathrm{pEXP} 2::$ eng $Y$. This expression vector fuses a 6-histidine tag to the C-terminal end of the EngY protein. pEXP2::eng $Y$ was transformed into chemically competent $E$. coli $\mathrm{DH} 10 \beta$ by heat shock. The plasmid was extracted and the construct was confirmed by PCR, sequencing, and restriction analysis to confirm that the insertion had been cloned in-frame with no introduced mutations. pEXP2::eng $Y$ was introduced into the expression strain, $E$. coli BL21 (DE3) pLysS, by electroporation. Single colonies were chosen and grown to $\mathrm{OD}_{600}=0.5$. Protein expression was induced once the cell density reached $\mathrm{OD}_{600}=0.5$ by adding isopropyl $\beta$-D-1-thiogalactopyranoside to a final concentration of $1 \mathrm{mM}$. Cultures were grown at $37^{\circ} \mathrm{C}$ to $\mathrm{OD}_{600}=1.0$. E. coli strain BL21 (DE3) pLysS transformed with the control vector pEXP2-DEST::lacZ supplied with the pEXP2-DEST cloning kit was used as negative control. Protein extraction, purification, and enzymatic assays were performed as described above for P. stewartii subsp. stewartii.

\section{Virulence assays.}

Seed of sweet corn ('Jubilee') (Syngenta Seeds, Boise, ID, U.S.A.) were propagated in a Marathon-treated mixture of peat and vermiculite under greenhouse conditions. Single colonies of either P. stewartii subsp. stewartii DC283, $\Delta e n g Y$, or $\Delta e n g Y$ (pBBR1::engY) were grown overnight, washed twice in $1 \times$ phosphate-buffered saline buffer (PBS), and resuspended in the same buffer to $\mathrm{OD}_{600}=1.0$. For the stab-inoculation assay, 14-day-old corn seedlings were stab inoculated six times in the stem slightly below the primary leaf using a sterile 20 -gauge syringe needle (Becton Dickinson) and $5 \mu \mathrm{l}$ (approximately $10^{7}$ cells) of bacterial inoculum was placed over the wound. For the whorl-inoculation assay, the whorls of 7-day-old sweet corn (Jubilee) seedlings were inoculated with $150 \mu \mathrm{l}$ of a $10^{7}$ $\mathrm{CFU} / \mathrm{ml}$ suspension of WT $P$. stewartii subsp. stewartii DC283, $\Delta e n g Y$, or $\Delta e n g Y$ (pBBR1::eng $Y$ ) or $1 \times$ PBS buffer to assess water-soaking ability (Coplin et al. 1986). Seedlings were assessed daily for symptom development and rated using an arbitrary disease index scale where $0=$ no symptoms; $1=$ small water-soaking lesions; 2 = larger water-soaking lesions; 3 = water-soaking lesions, ooze, and slight wilting; $4=$ severe wilting; and $5=$ dead. Seedlings inoculated with $1 \times$ PBS buffer were used as negative controls. Both experiments were repeated three times with at least 10 technical replicates for each experiment.

\section{In planta movement assay.}

Plasmid pHC60 harboring the $g f p_{\text {S65t }}$ gene (Cheng and Walker 1998) was conjugally transferred into the $P$. stewartii subsp. stewartii DC283, $\Delta e n g Y$, and $\Delta e n g Y$ (pBBR1::eng $Y)$ strains to create strains DC283 (pHC60::gfp), $\Delta e n g Y$ (pHC60::gfp), and $\Delta e n g Y$ (pBBR1::eng $Y$, pHC60::gfp), respectively. Inoculum was prepared by growing the GFP-tagged strains overnight in $2 \mathrm{ml}$ of $\mathrm{LB}$ broth containing the appropriate antibiotics, washing twice in $1 \times$ PBS, and resuspending in $1 \times$ PBS buffer. Cell density was adjusted to $\mathrm{OD}_{600}=1.0$. Fourteen-day-old sweet corn seedlings were stab inoculated in the leaf midrib using a sterile syringe needle and $5 \mu \mathrm{l}$ of inoculum was placed over the stab wound. Bacterial movement within the leaf tissue was monitored $72 \mathrm{~h}$ after inoculation using a Leica fluorescence stereoscope Fluo Tm equipped with a Hg Arc lamp as described by Herrera and associates (2008). The distances traveled acropetally and basipetally from the inoculation site were measured.

\section{ACKNOWLEDGMENTS}

Funding for this project was awarded to M. C. Roper by the Regents of the University of California, Riverside and the Agricultural Experiment Station and College of Natural and Agricultural Sciences. We thank J. Labavitch (University of California, Davis) and J. Clifford and P. Rolshausen (University of California, Riverside) for critical reading of this manuscript and for their helpful suggestions, and M. Daugherty (University of California, Riverside) for assistance with the statistical analysis performed for this study.

\section{LITERATURE CITED}

Baron-Epel, O., Paramjit, K., Gharyal, K., and Schindler, M. 1988. Pectins as mediators of wall porosity in soybean cells. Planta 175:389-395.

Bauer, W. D., Talmadge, K. W., Keegstra, K., and Albersheim, P. 1973. Structure of Plant-Cell Walls 2. Hemicellulose of walls of suspensioncultured sycamore cells. Plant Physiol. 51:174-187.

Bayer, E. A., Belaich, J. P., Shoham, Y., and Lamed, R. 2004. The cellulosomes: multienzyme machines for degradation of plant cell wall polysaccharides. Annu. Rev. Microbiol. 58:521-554.

Beck von Bodman, S., and Farrand, S. K. 1995. Capsular polysaccharide biosynthesis and pathogenicity in Erwinia stewartii require induction by an $\mathrm{N}$-acylhomoserine lactone autoinducer. J. Bacteriol. 177:50005008

Boccara, M., J. L. Aymeric, and Camus, C. 1994. Role of endoglucanases in Erwinia chrysanthemi 3937 virulence on Saintpaulia ionantha. J. Bacteriol. 176:1524-1526.

Boyer, M. H., Cami, B., Chambost, J. P., Magnan, M., and Cattaneo, J. 1987. Characterization of a new endoglucanase from Erwinia chrysanthemi. Eur. J. Biochem. 162:311-316.

Bradbury, J. F. 1967. CMI Description of Pathogenic Fungi and Bacteria. CAB International, Wallingford, U.K.

Bradford, M. M. 1976. A rapid and sensitive method for the quantitation of microgram quantities of protein utilizing the principle of protein-dyebinding. Anal. Biochem. 72:248-254.

Buchanan, B. B., Gruissem, W., and Jones, R. L. 2000. Biochemistry and molecular biology of plants. Pages 52-100 in: The Cell Wall. American Society of Plant Physiologists, Rockville, MD, U.S.A

Carlier, A., Burbank, L. and von Bodman, S. B. 2009. Identification and characterization of three novel Esal/EsaR quorum-sensing controlled stewartan exopolysaccharide biosynthetic genes in Pantoea stewartii ssp. stewartii. Mol. Microbiol. 74, 903-913.

Carpita, N. C. 1996. Structure and biogenesis of the cell walls of grasses. Annu. Rev. Plant Physiol. Plant Mol. Biol. 47:445-476.

Cheng, H. P, and Walker, G. C. 1998. Succinoglycan is required for initiation and elongation of infection threads during nodulation of alfalfa by Rhizobium meliloti. J. Bacteriol. 180:5183-5191.

Choat, B., Ball, M., Luly, J., and Holtum, J. 2003. Pit membrane porosity and water stress-induced cavitation in four co-existing dry rainforest tree species. Plant Physiol. 131:41-48.

Choi, K. H., and Schweizer, H. P. 2005. An improved method for rapid generation of unmarked Pseudomonas aeruginosa deletion mutants. BMC Microbiol. 5:30.

Claflin, L. E., ed. 2000. Stewart's bacterial wilt. In: Compendium of Corn Diseases, 3rd ed. D. G. White, ed. The American Phytopathological Society, St. Paul, MN, U.S.A.

Coplin, D. L., Frederick, R. D., Majerczak, D. R., and Haas, E. S. 1986. Molecular cloning of virulence genes from Erwinia stewartii. J. Bacteriol. 168:619-623.

Datsenko, K. A., and Wanner B. L. 2000. One-step inactivation of chromosomal genes in Escherichia coli K-12 using PCR products. Proc. Natl. Acad. Sci. U.S.A. 97:6640-6645

De Maayer, P., Chan, W. Y., Venter, S. N., Toth, I. K., Birch, P. R., Joubert, F., and Coutinho, T. A. 2010. Genome sequence of Pantoea ananatis LMG20103, the causative agent of Eucalyptus blight and dieback. J. Bacteriol. 192:2936-2937.

Dolph, P. J., Majerczak, D. R., and Coplin, D. L. 1988. Characterization of a gene cluster for exopolysaccharide biosynthesis and virulence in Erwinia stewartii. J. Bacteriol. 170:865-871

Dow, J. M., Clarke, B. R., Milligan, D. E., Tang, J. L., and Daniels, M. J. 1990. Extracellular proteases from Xanthomonas campestris pv. cam- 
pestris, the black rot pathogen. Appl. Environ. Microbiol. 56:29942998.

Dow, J. M., Davies, H. A., and Daniels, M. J. 1998. A metalloprotease from Xanthomonas campestris that specifically degrades proline/hydroxyproline-rich glycoproteins of the plant extracellular matrix. Mol. Plant-Microbe Interact. 11:1085-1093.

Dygert, S., Li, L. H., Florida, D., and Thoma, J. A. 1965 Determination of reducing sugar with improved precision. Anal. Biochem. 13:367-374.

Esau, K. 1965. Plant Anatomy, 2nd ed. J. Wiley and Sons Inc., New York.

Gibeaut, D. M., and Carpita, N. C. 1994. Biosynthesis of plant cell wall polysaccharides. FASEB (Fed. Am. Soc. Exp. Biol.) J. 8:904-915.

Glasner, J. D., Rusch, M., Liss, P., Plunkett, G. 3rd, Cabot, E. L., Darling, A., Anderson, B. D., Infield-Harm, P., Gilson, M. C., and Perna, N. T. 2006. ASAP: A resource for annotating, curating, comparing, and disseminating genomic data. Nucleic Acids Res. 34:D41-45.

Gonzalez, E. T., and Allen, C. 2003. Characterization of a Ralstonia solanacearum operon required for polygalacturonate degradation and uptake of galacturonic acid. Mol. Plant-Microbe Interact. 16:536-544.

Gough, C. L, Dow, M. J., Barber, C. E., and Daniels, M. J. 1988. Cloning of two endoglucanase genes of Xanthomonas campestris pv. campestris: analysis of the role of the major endoglucanase in pathogenesis. Mol. Plant-Microbe Interact. 1:275-281.

Herrera, C. M., Koutsoudis, M. D., Wang, X., and von Bodman, S. B. 2008. Pantoea stewartii subsp. stewartii exhibits surface motility, which is a critical aspect of Stewart's wilt disease development on maize. Mol. Plant-Microbe Interact. 21:1359-1370.

Hoang, T. T., Karkhoff-Schweizer, R. R., Kutchma, A. J., and Schweizer, H. P. 1998. A broad-host-range Flp-FRT recombination system for sitespecific excision of chromosomally located DNA sequences: application for isolation of unmarked Pseudomonas aeruginosa mutants. Gene 212:77-86.

Hoson, T., Masuda, Y., and Nevins, D.J. (1992) Comparison of the outer epidermis: inhibition of auxin-induced elongation of maize coleoptiles by glucan antibodies. Plant Physiol. 98:1298-1303.

Huang, Q., and Allen, C. 1997. An exo-poly-alpha-D-galacturonosidase, $\mathrm{PehB}$, is required for wild-type virulence of Ralstonia solanacearum. J. Bacteriol. 179:7369-7378.

Huang, Q., and Allen, C. 2000. Polygalacturonases are required for rapid colonization and full virulence of Ralstonia solanacearum on tomato plants. Physiol. Mol. Plant Pathol. 57:77-83.

Inouhe, M., and Nevins, D. J. 1991a. Auxin-induced glucan autohydrolysis in maize coleoptile cell walls. Plant Physiol. 96:285-290.

Inouhe, M., and Nevins, D. J. 1991b. Inhibition of auxin-induced cell elongation of maize coleoptiles by antibodies specific for cell wall glucanases. Plant Physiol. 96:426-431.

Kamoun, S., and Kado, C. I. 1990. A Plant-Inducible Gene of Xanthomonas campestris pv. campestris encodes an exocellular component required for growth in the host and hypersensitivity on Nonhosts. J. Bacteriol. 172:5165-5172.

Kaniga, K., Delor, I., and Cornelis, G. R. 1991. A wide-host-range suicide vector for improving reverse genetics in gram-negative bacteria: Inactivation of the blaA gene of Yersinia enterocolitica. Gene 109:137-141.

Keegstra, K., Talmadge, K. W., Bauer, W. D., and Albersheim, P. 1973. The structure of plant cell walls. III. A model of the walls of suspension-cultured sycamore cells based on the interconnections of the macromolecular components. Plant Physiol. 51:188-196.

Kovach, M. E., Elzer, P. H., Hill, D. S., Robertson, G.T. , Farris, M. A., Roop, R. M., and Peterson, K. M. 1995. 4 New Derivatives of the broad host-range cloning vector pBBR1MCS, carrying different antibiotic resistance cassettes. Gene 166:175-176.

Labavitch, J. M., and Greve, L. C. 1983. Cell wall metabolism in ripening fruit. 3. Purification of an endo-beta-1,4-xylanase that degrades a structural polysaccharide of pear fruit cell walls. Plant Physiol. 72:668-673.

Leigh, J. A., and Coplin, D. L. 1992. Exopolysaccharides in plant-bacterial interactions. Annu. Rev. Microbiol. 46:307-346.

Liu, H., Zhang, S., Rodriguez, C., Schell, M. A., and Denny, T. P. 2004. Pyramiding unmarked mutations in Ralstonia solanacearum to assess the role of extracellular enzymes in pathogenesis. (Abstr.) Phytopathology 94:S62.

Nimtz, M., Mort, A. , Wray, V., Domke, T., Zhang, Y., Coplin, D. L., and Geider, K. 1996. Structure of stewartan, the capsular exopolysaccharide from the corn pathogen, Erwinia stewartii. Carbohydr. Res. 288:189-201.

Pataky, J.K. 2004. Stewart's wilt of corn. In: The Plant Health Instructor doi:10.1094/PHI-I-2004-0113-01. Published online.

Perez-Donoso, A. G., Sun, Q., Roper, M. C., Greve, L. C., Kirkpatrick, B., and Labavitch, J. M. 2010. Cell wall-degrading enzymes enlarge the pore size of intervessel pit membranes in healthy and Xylella fastidiosainfected grapevines. Plant Physiol. 152:1748-1759.

Ray, S. K., Rajeshwari, R., and Sonti, R. V. 2000. Mutants of Xanthomonas oryzae pv. oryzae deficient in general secretory pathway are virulence deficient and unable to secrete xylanase. Mol. Plant-Microbe Interact. 13:394-401.

Roberts, D. P., Denny, T. P., and Schell, M. A. 1988. Cloning of the egl gene of Pseudomonas solanacearum and analysis of its role in phytopathogenicity. J. Bacteriol. 170:1445-1451.

Roper, M. C., Greve, L. C., Warren, J. G., Labavitch, J. M., and Kirkpatrick, B. C. 2007. Xylella fastidiosa requires polygalacturonase for colonization and pathogenicity in Vitis vinifera grapevines. Mol. Plant-Microbe Interact. 20:411-419.

Saile, E., McGarvey, J. A., Schell, M. A., and Denny, T. P. 1997. Role of extracellular polysaccharide and endoglucanase in root invasion and colonization of tomato plants by Ralstonia solanacearum. Phytopathology 87:1264-1271.

Shane, M. W., McCully, M. E., and Canny, M. J. 2000. Architecture of branch-root junctions in maize: structure of the connecting xylem and the porosity of pit membranes. Ann. Bot. 85:613-624.

Sun, Q., Greve, L. C., and Labavitch, J. M. 2011. Polysaccharide compositions of intervessel pit membranes contribute to Pierce's disease resistance of grapevines. Plant Physiol. 155:1976-1987.

Zimmerman, M. H. 1983. Xylem Structure and the Ascent of Sap. SpringerVerlag, New York.

Zwieniecki, M. A., Melcher, P. J., and Holbrook, N. M. 2001. Hydrogel control of xylem hydraulic resistance in plants. Science 291:1059-1062.

\section{AUTHOR-RECOMMENDED INTERNET RESOURCE}

University of Wisconsin-Madison ASAP (a systemic annotation package for community analysis of genome) database: asap.ahabs.wisc.edu/asap/home.php 